\title{
Two cases of Ellis-van Creveld syndrome in a small island population
}

\author{
R. D. HILL \\ From Island of Barra, Outer Hebrides, Scotland
}

SUMMARY Two individuals showing features typical of the autosomal recessive Ellis-van Creveld syndrome have been diagnosed in a population of 1340 individuals living on a small island off the west coast of Scotland. Clinical features and family relationships of the affected individuals are described.

In 1940 R. W. B. Ellis and S. van Creveld described a new syndrome of chondroectodermal dysplasia. The syndrome is characterized by (1) ectodermal dysplasia, (2) polydactyly, (3) chondrodysplasia, and (4) congenital morbus cordis. At least 3 of the 4 criteria are required for diagnosis.

Nabrady (1961) separated out the constant from the inconstant findings in this syndrome and these may be summarized as follows:

(1) Dwarfism, caused by progressive distal shortening of the extremities. (2) Manual polydactyly, the site of the extra 6 th or 7 th digit being in every case on the ulnar side of the hand. (3) Fusion of the capitate and hamate bones. (4) Delayed ossification of the primary centre and accelerated ossification of the secondary centre of the metacarpals and phalanges. (5) Characteristic changes of the proximal ends of the tibial epiphyses, that is of the low peaked metaphyses with short medial slopes and relatively long lateral slopes, the medial slopes capped by a triangularly shaped ossification centre in the epiphysial cartilage. These changes, which are pathognomonic of the syndrome, account for the genu valgum which is usually present. (6) The proximal end of the ulnae and the distal end of the radii are greatly enlarged, leading eventually to the dislocation of the radial heads and narrowing of elbow activity. (7) Ectodermal dysplasia, usually consisting of irregularly spaced, partly dysplastic and partly aplastic teeth, which occurs in both deciduous and permanent teeth. There is hypoplasia of the nails which are set back on the fingertips with increased friability of the nails.

Inconstant features are numerous; congenital heart disease occurs in $50 \%$ of reported cases (Tubbs

Received for publication 1 June 1976 et al., 1962) and obliteration of the sulcus between the upper lip and the gum, and hypoplasia of the mid portion of the upper lip, giving the appearance of harelip have been reported. Polydactylism or syndactylism of the feet, arthrogryposis, epispadias, hypospadias, hypoplasia of the acetabulum, and deformity of the thorax have all been reported. No sexual or racial predominance has been noted, but McKusick et al. (1964) have pointed out the unusually high frequency of Ellis-van Creveld syndrome among the Old Order Amish of Pennsylvania when, with 41 cases of the syndrome reported world-wide up to 1964, they discovered 43 definite cases in 26 sibships among the Amish of Eastern Pennsylvania. The condition is inherited as an autosomal recessive syndrome.

This paper describes two certain cases and one probable case of the Ellis-van Creveld syndrome in a small isolated island practice in the Outer Hebrides. The practice is in the island of Barra, off the west coast of Scotland, and covers a population of 1340 individuals.

\section{Case reports}

Miss M. McD. (IV.1) born in 1942 at full term (wt. $3402 \mathrm{~g}$ ) after an uncomplicated pregnancy and labour. She was small as a very young child, and because of her size did not start school until the age of $6 \frac{1}{2}$. She runs a small croft unaided.

Apart from migrainous headaches and symptoms related to a displaced cartilage in her (L) knee she had not complained of ill health. She is of normal intelligence and has a very good singing voice. She leads an active social life and is in demand to sing at ceilidhs and on the radio. 


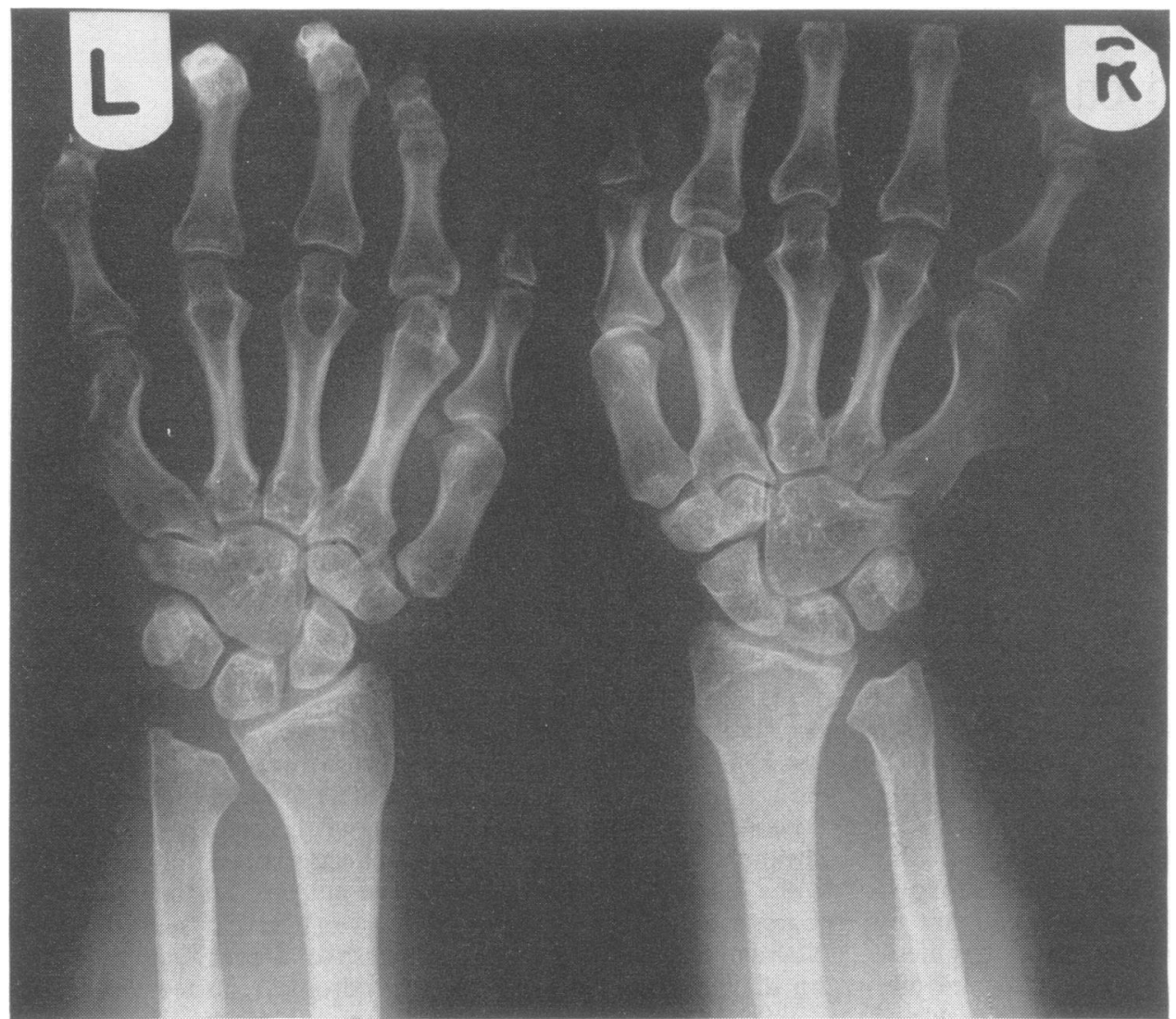

Fig. 1 X-ray films of hands and wrists of IV.I (M.McD.) showing typical stigmata of Ellis-van Creveld syndrome.

She is $136 \mathrm{~cm}$ tall; weight $59 \mathrm{~kg}$; crown to pubic measurements $78.5 \mathrm{~cm}$; pubis to sole $56 \mathrm{~cm}$. There was pronounced kyphoscoliosis of the thoracic spine but dwarfing was mainly caused by shortening of the lower limbs and of the distal segments in particular. (Thigh length $28 \mathrm{~cm}$; tibial length $18 \mathrm{~cm}$.) Arms were short (span $125 \mathrm{~cm}$ ), the shortening affecting the forearm $(19.5 \mathrm{~cm})$ more than the upper $\operatorname{arm}(27 \mathrm{~cm})$. Fingers and toes were short and stumpy and the nails absent or atrophic. Both hands bore scars of amputation of sixth fingers. Fig. 1, which is an $x$-ray film of the hand and wrists, shows the proximal phalanges to have a normal length, and the middle and distal phalanges to be very small. The wrist bones have the typical appearance of fusion of the capitate and hamate bones. The sites of origin of the sixth digits are seen on the ulnar sides of the 5 th metacarpals. Hair and teeth are normally developed.

The other noteworthy findings were in the cardiovascular system. She is short of breath on exertion, she is not cyanosed, her pulse is of small volume with frequent extrasystoles but is otherwise normal, her venous pressure is not raised, and her cardiac impulse suggests some right ventricular hypertrophy. On auscultation she has loud systolic murmurs at the apex and at the base and a high-pitched diastolic murmur at the left sternal edge. There is also a mild diastolic murmur midway between the left sternal edge and the apex. She has close but fixed splitting of the 2 nd sound in the pulmonary area.

Chest $x$-ray shows plethoric lung fields, right atrial enlargement, and a small aorta. The electrocardiogram shows right atrial hypertrophy and left axis deviation.

Clinically, this suggested a diagnosis of an atrial septal defect and in view of the left axis deviation on the electrocardiogram this was thought to be of the ostium primum variety.

Cardiac catheterization was carried out.

Dye dilution tests showed a right-to-left shunt at atrial level. This was confirmed by oxygen saturation 
tests which showed: in the superior vena cava $\mathbf{O}_{2}$ saturation of $72 \%$, inferior vena cava $78 \%$, mid right atrium $89 \%$, right ventricle $94 \%$, pulmonary artery $93 \%$, and arterial oxygen saturation was $96 \%$. This is indicative of a right-to-left shunt at atrial level and from the dye curves it is concluded that the pulmonary blood flow is 2 to 3 times greater than the systemic blood flow.

The patient, in spite of her heart lesion, underwent operation for the correction of her 'knock-knees' (resulting from defects of the lateral aspects of the proximal ends of her tibiae). The operation was very successful both from a technical point of view and because, whereas, before the operation she had been shy of her appearance and had sung in public from the back rows of the hall, she now went up on the stage to sing and even took part in amateur theatrical performances.

Patient Mr H. McK. (IV.2) was a cousin of the first patient. This man was born in 1925 . He was one of twins (his brother, who also had 6 fingers, had multiple congenital abnormalities and lived only 24 hours (IV.3)). He had enjoyed good health all his life until at the age of 40 he complained of headaches and epistaxis and was diagnosed as suffering from essential hypertension in an accelerated phase.

For many years he owned and operated a mobile grocery store in Barra and at one time he even worked on the road gang, but he then left Barra to run a tobacconist and confectioner's shop in Glasgow.

He was $152.5 \mathrm{~cm}$ tall and weighed $60 \mathrm{~kg}$. The shortening was most apparent in his limbs (crown to pubis $91 \mathrm{~cm}$, pubis to sole $61 \mathrm{~cm}$, span $110 \mathrm{~cm}$ ) and especially in the distal segment of his limbs.

There was a well-developed sixth digit on each hand but a normal complement of toes. Fig. 2 is an $x$-ray film of his hands and wrists and shows fusion of left capitate and hamate but normal wrist on the (R) side. The sites of origin of the extra digits can be seen on the ulnar sides of the 5th metacarpals.

The hard palate and alveolar margins were defective anteriorly and he had never developed upper central incisors. Other teeth were small in size and had defective enamel.

He had had a left ectopic testis and associated inguinal hernia which were operated on in 1961.

In 1965 he was found to have a blood pressure of $220 / 150 \mathrm{mmHg}$ and a blood urea of $71 \mathrm{mg} / 100 \mathrm{ml}$ $(11.8 \mathrm{mmol} / \mathrm{l})$. His optic fundi showed grade 4 changes. Urea clearance was $31 \%$ showing considerable renal damage. Electrocardiogram showed left ventricular strain. There were no indications of congenital heart abnormalities, all the tests indicating that the results were caused by his essential hypertension.

Treatment was started but never produced satifactory results and he died in March 1967 from

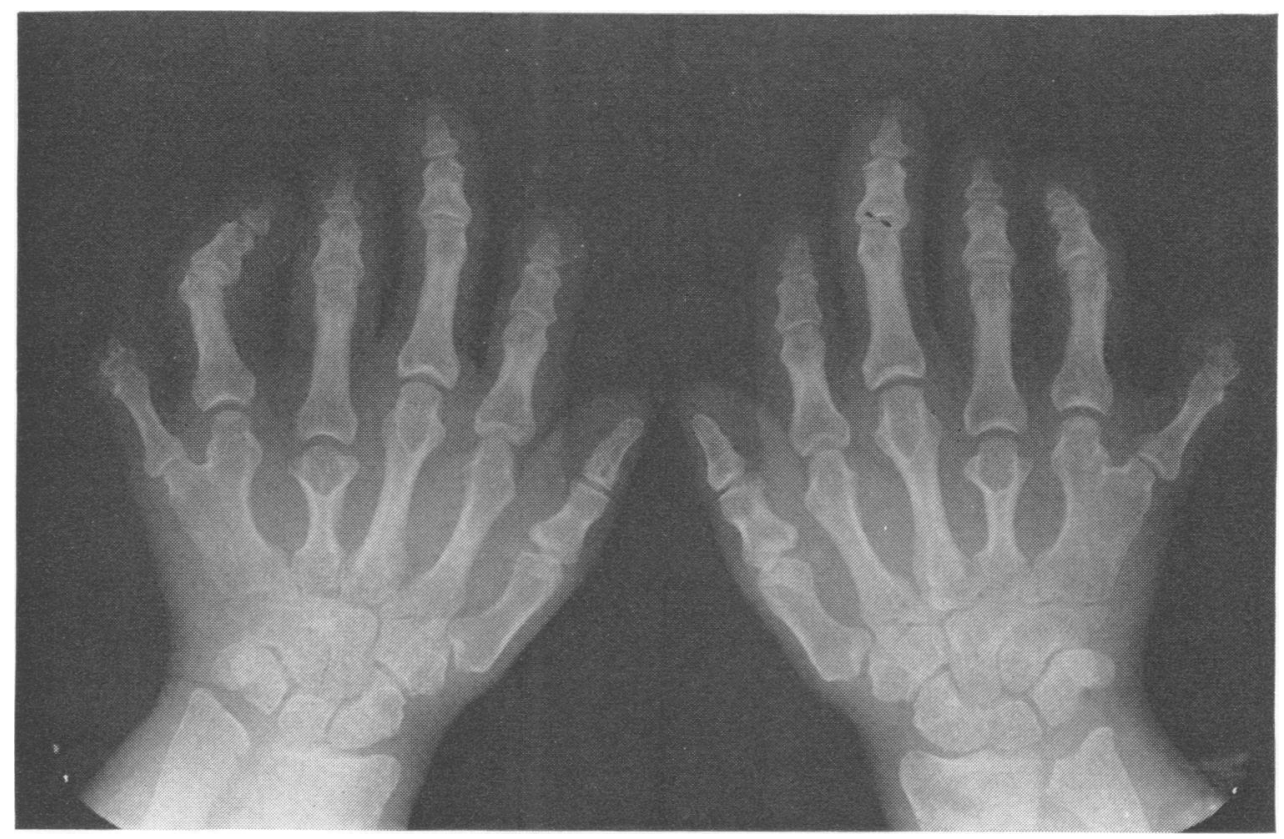

Fig. $2 X$-ray films of hands and wrists of IV.2 (H. McK.) showing typical stigmata of Ellis-van Creveld syndrome. 


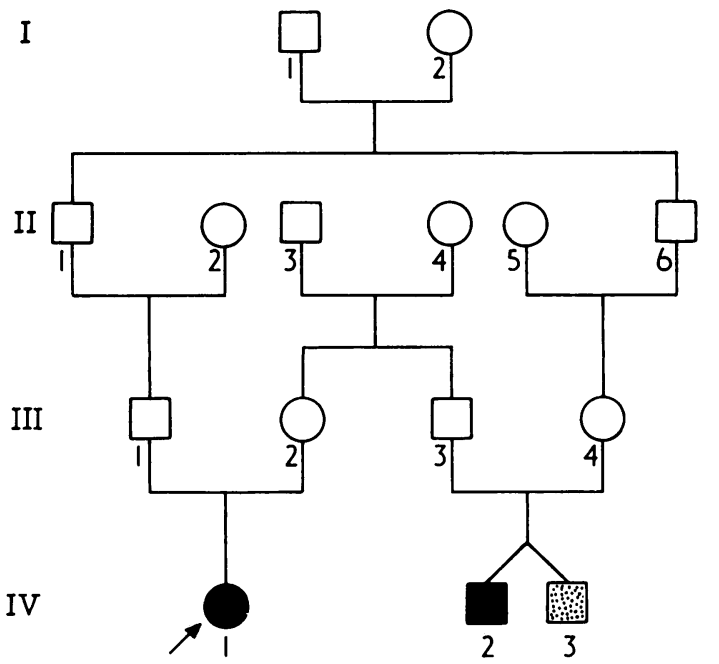

Fig. 3 Family tree showing the two propositi and the twin of one, who was probably also an Ellis-van Creveld sufferer, showing their interrelationship.

chronic left heart failure. A necropsy was not performed.

\section{Discussion}

These patients were clear cases of Ellis-van Creveld syndrome, one (M.McD.) satisfying all 4 of the criteria and the other (H.McK.) satisfying 3 out of the 4 criteria.

The family tree in Fig. 3 shows that two cousins married a brother and a sister, but though the family tree has been traced back for 5 generations no evidence of any other case of Ellis-van Creveld syndrome has been discovered in the ancestry of these patients. Inquiry to elicit a 'folk memory' of a 'dwarf' on the island has been equally unavailing though a 'giant' from the middle of the nineteenth century is still well remembered.

The founder for this gene probably occurred as a mutant or a migrant in the eighteenth century or before, and the long waiting time to homozygosis is to be expected in a population with as large an evolutionary size as Barra (Morton et al., 1976).

I am grateful to Dr W. H. Price and Mrs Anna Frackiewicz of the MRC Clinical and Population Cytogenetics Unit, Edinburgh, for clinical details of Miss McD's heart lesion and for authenticating the family tree.

\section{References}

Ellis, R. W. B., and van Creveld, S. (1940). A syndrome characterised by ectodermal dysplasia, polydactyly, chondrodysplasia and congenital morbus cordis. Archives of Disease in Childhood, 15, 65-84.

McKusick, V. A., Engeland, J. A., Eldridge, R., and Krusen, D. E. (1964). Dwarfism in the Amish. I. The Ellis-van Creveld syndrome. Bulletin of the Johns Hopkins Hospital, 115, 306-336.

Morton, N. E., Smith, C., Hill, R. D., Frackiewicz, A., Law, P., and Yee, S. (1976). Population structure of Barra (Outer Hebrides). Annals of Human Genetics, 39, 339-352.

Nabrady, J. (1961). Ellis-van Creveld syndrome. Neuroectodermal injury. Annales paediatrici, 196, 18.

Tubbs, F. E., Crevasse, L., and Green, J. R. (1962). Congenital heart disease in an adult with the Ellis-van Creveld syndrome. Annals of Internal Medicine, 57, 829-834. 